\title{
Confusion still exists regarding postoperative delirium and its etiology after esophagectomy
}

\author{
Robert B. Cameron, MD
}

\footnotetext{
From the Division of Thoracic Surgery, Department of Surgery, David Geffen School of Medicine at UCLA, Los Angeles, Calif; and the Division of Thoracic Surgery, Department of Surgery and Perioperative Care, West Los Angeles VA Medical Center, Los Angeles, Calif.

Disclosures: Author has nothing to disclose with regard to commercial support.

Received for publication Nov 14, 2017; accepted for publication Nov 16, 2017.

Address for reprints: Robert B. Cameron, MD, Division of Thoracic Surgery, Department of Surgery, David Geffen School of Medicine, 10780 Santa Monica Blvd, Suite 100, Los Angeles, CA 90025 (E-mail: rcameron@ stanfordalumni.org).

J Thorac Cardiovasc Surg 2018;155:1331-2

$0022-5223 / \$ 36.00$

Copyright (c) 2017 by The American Association for Thoracic Surgery

https://doi.org/10.1016/j.jtcvs.2017.11.052
}

Patients undergoing esophagectomy remain one of the most difficult patient groups in thoracic surgery to manage successfully, both perioperatively and postoperatively. Numerous factors influence both morbidity and mortality, including age; sex; preexisting comorbidities, such as pulmonary disease, cardiovascular disease, renal failure, and diabetes; and American Society of Anesthesiologists score. One of the most vexing postoperative problems in this patient group is delirium. Risk factors for postoperative delirium, as pointed out by Jung and colleagues ${ }^{1}$ in their article in this issue of the Journal, include many of the factors listed as well as others, such as intensive care and opioid medication use. ${ }^{2}$ Postoperative delirium and its treatment, which often includes medications with sedative properties, further increase the risk of other postoperative complications, particularly pulmonary problems. Although preventive measures, such as avoidance of opioid and psychotropic medications, promotion of nocturnal sleep, and minimizing intensive care stays, may diminish the incidence and severity of postoperative delirium, the use of specific fluids, such as hydroxyethyl starch (HES), for perioperative resuscitation has not to date been associated with either increased or decreased postoperative delirium. Jung and colleagues, ${ }^{1}$ in their retrospective review of factors associated with postoperative delirium in 980 patients undergoing esophagectomy between April 2010 and February 2015, surprisingly implicate the use of HES for perioperative resuscitation in 509 patients as an important factor. This unexpected finding is potentially important, but it also must be interpreted in the context of the study as well as other available information.

First, although Jung and colleagues' report ${ }^{1}$ includes relatively current data, from within the past 7 years, and is propensity matched, it is still retrospective. Furthermore, the choice of resuscitation fluid was far from random, with the determination made by the attending anesthesiologist on

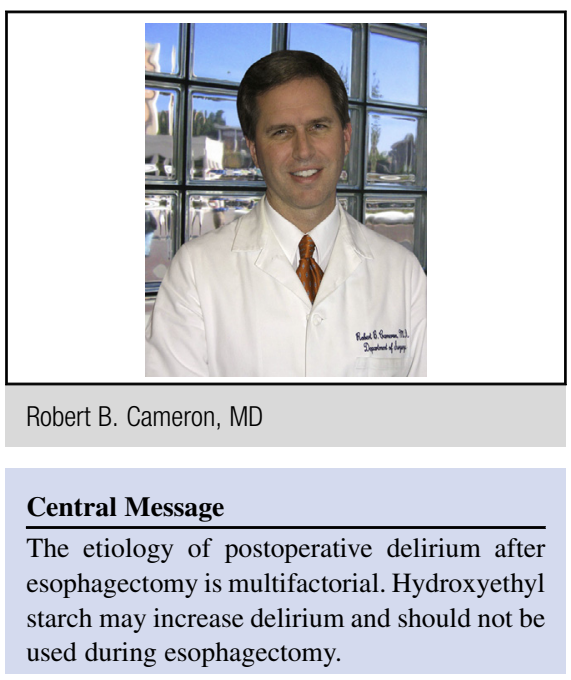

See Article page 1333.

the basis of unspecified and unknown factors. Interestingly, vasoactive drugs, often avoided in many centers, were allowed both perioperatively and postoperatively - a practice that may have contributed to an underlying acidosis and secondarily to postoperative delirium. HES use previously has been associated with the development of renal dysfunction in patients specifically undergoing resuscitation or esophagectomy. The same group noted this in a subgroup of these patients, prompting their conclusion that "HES should be administered with caution" solely because of the risk of renal impairment. ${ }^{3,4}$ Renal impairment and acidosis both may thus have contributed to the development of postoperative delirium in HESresuscitated patients. One additional factor to note is that all procedures were performed exclusively through open approaches, both thoracotomy and laparotomy. The same group, in a separate publication comparing minimallyinvasive robotic esophagectomy with a propensitymatched group of these same patients, noted a reduction in the incidence of postoperative delirium by 0.55 times strictly from the use of a minimally invasive approach.

All the issues discussed raise caution flags regarding both the interpretation of this intriguing study and the use of HES in patients undergoing esophagectomy. Regardless of these findings, no evidence exists currently in the medical literature to support the use of HES during esophagectomy, and there may be detrimental effects. HES should therefore 
not be used outside well-designed, institutional review board-approved clinical trials.

\section{References}

1. Jung DM, Ahn HJ, Yang M, Kim JA, Kim DK, Lee SM, et al. Hydroxyethyl starch is associated with early postoperative delirium in patients undergoing esophagectomy. J Thorac Cardiovasc Surg. 2018;155:1333-43.

2. Yamamoto M, Yamasaki M, Sugimoto K, Maekawa Y, Miyazaki Y, Makino T, et al. Risk evaluation of postoperative delirium using comprehensive geriatric assessment in elderly patients with esophageal cancer. World J Surg. 2016;40: 2705-12.
3. Zarychanski R, Abou-Setta AM, Turgeon AF, Houston BL, McIntyre L, Marshall JC, et al. Association of hydroxyethyl starch administration with mortality and acute kidney injury in critically ill patients requiring volume resuscitation: a systematic review and meta-analysis. JAMA. 2013;309:678-88. Erratum in: JAMA. 2013;309:1229.

4. Ahn HJ, Kim JA, Lee AR, Yang M, Jung HJ, Heo B. The risk of acute kidney injury from fluid restriction and hydroxyethyl starch in thoracic surgery. Anesth Analg. 2016;122:186-93.

5. Jeong DM, Kim JA, Ahn HJ, Yang M, Heo BY, Lee SH. Decreased incidence of postoperative delirium in robot-assisted thoracoscopic esophagectomy compared with open transthoracic esophagectomy. Surg Laparosc Endosc Percutan Tech. 2016;26:516-22. 